\title{
ENVIRONMENTAL ISSUES DUE TO IMPROPER PLASTIC DISPOSAL IN INDIAN CITIES
}

\author{
T. Benson Solomon ${ }^{1}$, N.Nagarajan ${ }^{2}$ \\ ${ }^{1} P G$ Scholar, Department of Mechanical Engineering, Knowledge Institute of Technology, Tamilnadu, India \\ ${ }^{2}$ Assistant Professor, Department of Mechanical Engineering, Knowledge Institute of Technology, Tamilnadu, India
}

\begin{abstract}
Enormous amount of plastic is being used in our day to day life and no way we can avoid that and no way we can avoid that and the problem starts with the disposal or recycling of the plastic because there is no other method to make its contribution zero to the environment and all the survivals in the planet earth and this an major problem that have increased a lot in the past few decades. This finally ends up in slow poisoning of the fertile planet earth and the humans themselves make the planet a toxic zone. Day by day the scenario goes worse. This paper discusses about the proper means of plastic disposal and minimizes the contribution of plastic by our day to day routine.
\end{abstract}

Keywords: Plastic pollution, Plastic disposal, plastic recycling, environment.

\section{INTRODUCTION}

An overview of the past few years there has been a drastic change in the environment that happens due to various kinds of pollutions and in that a major part of contribution is done by plastic material and they cause hazard to the environment and also the survivors. Land has been polluted due to the release of chlorinated plastic, ocean has been polluted due to the nurdlesspilled into the ocean and also they harm creatures lives in salt waters. Animals are being harmed by improper disposal of plastic in land and also marine mammals. Finally human beings have been affected due to the plastics and the chemicals used in have a potential to cause hazard by inhaling contact with the skin and by consuming food products that are packed with plastic material

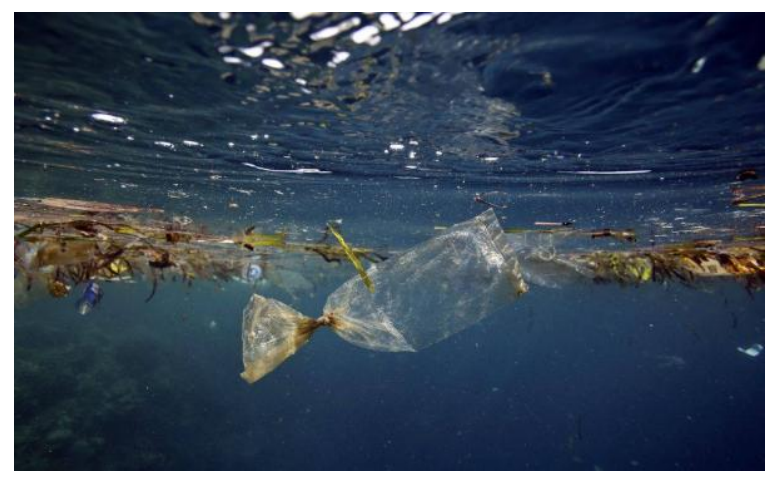

Not only that it goes without say that due to improper waste management system and enormous amount of plastics have been entered into the soil and that not only pollutes the soil but also makes the soil to loss its capacity to vegetate or allow trees to grow. This is one of the reason that plays a vital part of global warming and that again comes to slow poisoning of our planet earth. And also plastic is not a degradable or decomposable material and so when it is sedimented in the earths crust it will remain the same as such for more than three hundred years too. then an plastic is rapidly getting increased in an range of 1.7 to 300 million tones in the past 60 years [2].

Major chemicals used for plastic manufacturing (Polystyrene, poly vinyl chloride, Ethylene) and this contribute a very large proportion of plastic pollution that cause large number of unknown hazards in our day to day life [1].

\section{A BRIEF OF PLASTICS CONTRIBUTION TO}

\section{THE ENVIRONMENT}

It has been a very common activity in recent past that consuming plastics in our day to day routine is been unavoidable, were as in the past we have been using biodegradable material, for example (cotton bags banana leaves, fiber carriers).for transportation and holding of household usages but will now we have substituted all the above with plastic and materials ,made from that on no other go as our life style have been grown more faster so that we have to sustain our position.

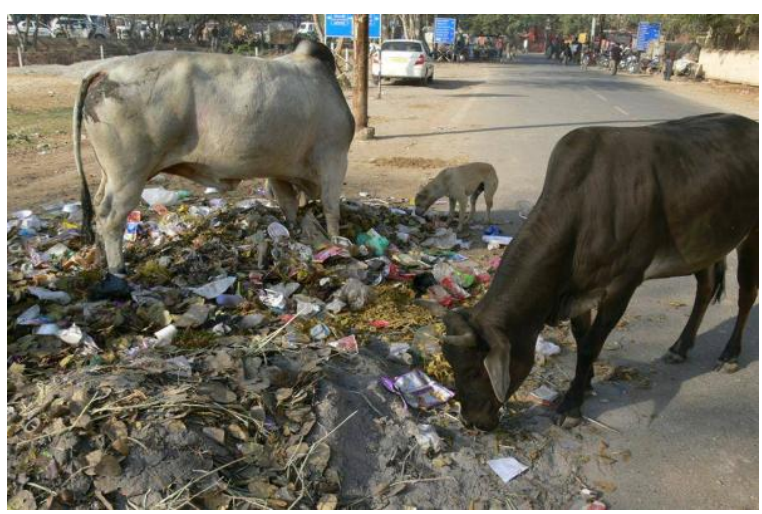


the increasing amount of usage of the plastic is polluting and poisoning our environment and there is very minimum chances to make usage of plastic zero level but there are chances to dispose them as they are meant to be and that may be very much effective to minimize our contribution of such an hazardous material into our planet because littering to be an major reason for pollution because with a proper methodology on manufacturing is being done and that have been ready for consumer and after consuming there starts the problem because their disposal occurs and due to improper disposal the process littering happens and they pay an root path to the environment to be polluted.

the consumers should be responsible for disposing the plastic with the proper means of disposing them but we fail to follow that and as a result tremendous amount of plastic is being exposed to the environment and thus we start poisoning our planet and then as a result planet is getting to worsen conditions day by day .

In India per capita generation of plastic waste in various cities varies from 0.0352 to $0.21 \mathrm{~kg} /$ person/day and plastic makes up between $8.9 \%$ of the component materials in the waste stream now most products are packed in polyethylene film, which reason $70 \%$ of municipal waste in the streams and that causes a major part of pollution all over [4].

\section{REASON STAND BACK IN LITTERING}

As preferred in previous pages our day to day disposal was a major component of pollution and the littering contributed by each plastic user when comes to hundreds thousands and millions of users. Increase of waste plastic is being extensively used and though be our self pollute our home and make our survival and worsen one and so. littering standard has a reason for plastic all sort of pollution and specially our plastic pollutions so the question here is by what means remove or avoid plastic and plastic waste from our circumstances and make our zone a plastic free zone.

Strategies that can be implemented for proper disposal of plastic waste. Appropriate measures should be taken by the Government like using medias and governmental Organizations to create awareness among people [3].

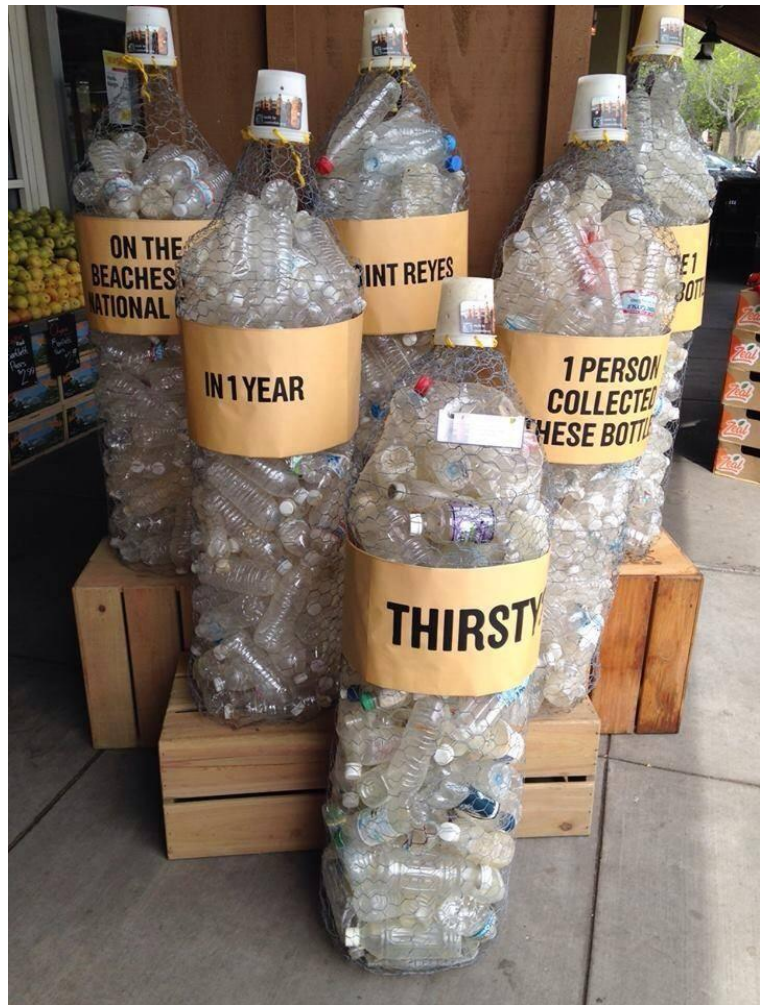

\section{METHOD}

\subsection{Method 1}

By minimizing the usage of plastic stands first because by that we can minimize the amount of consuming the plastic materials and that is implemented by usage of paper bag's thus it cost more we can increase the taxation or by making the paper carry bag payable and also by implementing law to produce paper carriers, paper cups and paper containers to meet high quality that can satisfies vendors and also consumers.

\subsection{Method II}

Enforcements of laws on excessive usage on manufacturing of use and throw plastics be made illegal up to an extend and littering of plastics in public places should be fired as other crimes are being done the norms on manufacturing should be followed and excessive amount of manufacturing should be minimized.

\subsection{Method III}

As some survey say's the rural, urban and also in corporate cities the collection and disposal should be made at a proper manner where us in Indian cities the disposal is carried out commonly for biodegradable and non bio degradable materials plastic belongs to non bio degradable material which should be separated from biodegradable material and all along are recycled though we are doing the above mentioned procedure. For larger amount of disposed and wasted plastic we want to carry out or adopt the same method 


\subsection{Method IV}

Keeping our environment clean is more important than keeping our home clean, and maintaining self responsibilities of disposal of plastic waste should be done by each person personally, rite from person one till it gets disposed or recycled the process tree should be done properly to achieve our goal (chart-1) and by implementing the process mentioned in the figure. We can able to minimize the plastic hazard to the environment.

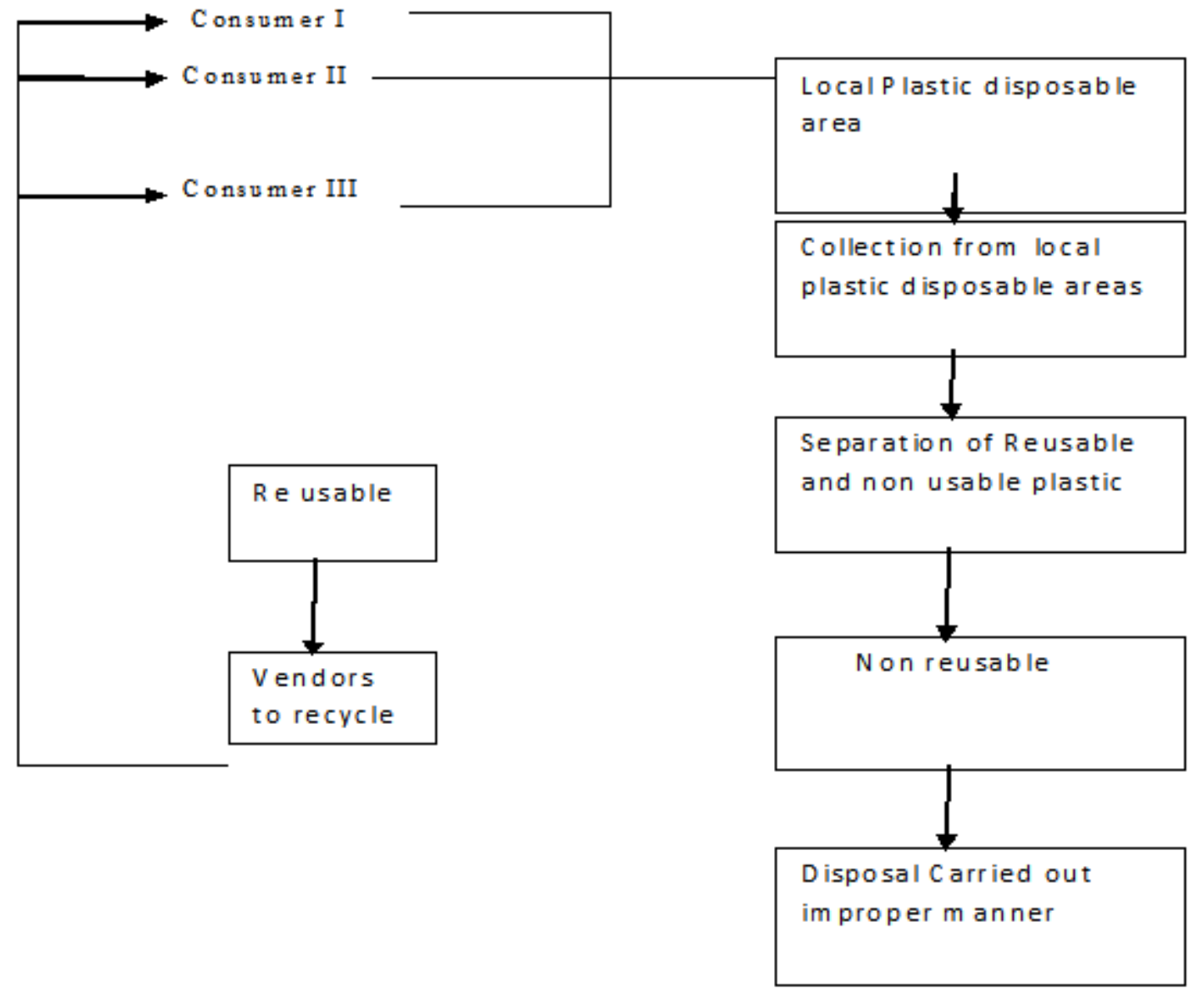

Chart-1 Prescribed plastic cycle for disposal

\section{SPECIAL NOTE AS A SUGGESTION}

A very good technology out of Japan called a "Blest Machine" which convert certain plastic into oil and if presently commercially available in sizes ranging from a batch processing to table top versions that is successfully used in homes of japan and that convert plastic composition like [Polyethylene, Polystyrene and poly propylene, PP, PE, PS] to oil, mean while, methane, ethane, propane and butane gases are released in the process and the machine is equipped of gas filtering and disintegrates these gases in to water and carbon. So by implementing this type of innovation we can reduce the plastics thread in our

\section{CONCLUSIONS}

Thus by implementing the above mentioned method and by adopting technique that are being created we can be able to reduce the hazard. We are facing and also to avoid extreme consequences from our nature. Thus the paper discusses and brief about the same thing which is already in words to be converted into action. Because that support to avoid worst situation and to maintain our planet earth remains green always and not only for our benefits but also its our own responsibility to leave our planet green for our next generation to and so its high time to get alarmed about the hazards contributed by plastics. Finally coming to end of our distribution the only thing we have to do this to adopt proper strategies that can dissolve plastics from our environment is the ultimate goal.

\section{REFERENCES}

[1] Aaron Lechnera., Hubert Keckeisa., Franz Lumesberger-Loisla., Bernhard Zensa., Reinhard Kruscha., Michael Tritthartb., Martin Glasb., Elisabeth Schludermanna.(2014). The Danube so colourful: A potpourri of plastic litter outnumbers fish larvae in Europe's second largest river. Environmental pollution 188, 177-181. 
[2] M. Punčochářa, B. Rujb, P. K. Chatterjeeb a(2012). Development of process for disposal of plastic waste using plasma pyrolysis technology and option for energy recovery. Procedia Engineering.42,420-430.

[3] Li Xudong. (2011)" Study on Environmental Pollution of Agriculture and Countermeasures under the Double Failure. Energy Procedia.5,204-208.

[4] Syeda Azeem Unnisa., and Bhuoatthi Rao.(2012).Plastic waste Management Strategies for Indian Cites. journal of chemical ,Biological and Physical Sciences.vol.2.no.1,514-518. 